\title{
El filósofo, el profeta, el hipócrita
}

\author{
PATRICIO PEÑALVER GÓMEZ \\ Universidad de Murcia
}

Este estudio propone una aproximación al pensamiento de Emmanuel Levinas tomando como hilo conductor el problema de la tensión o la diferencia greco-judía entendida como diferencia entre la ontología filosófica y la inspiración profético-mesiánica de una ética original. Se trata, en primer lugar, y con referencia a Totalidad e Infinito, de precisar la aporética interna de ese pensamiento, la contradicción entre su pro- grama de una ética abiertamente heterológica, y su fidelidad al discurso filosófico clásico. En segundo lugar, se señala una respuesta a esa dificultad del propio Levinas, en su segunda obra sistemática: De otro modo que ser o más alla de la esencia. En ésta, a partir de los "Tropos del lenguaje éticon, se propone un desplazamiento radicalmente no-ontológico del lenguaje filosofico.

A decir verdad desde que la escatología ha opuesto la paz a la guerra, la evidencia de la guerra se mantiene en una civilización esencialmente hipocrita, es decir, adherida a la vez a lo Verdadero y al Bien, en adelante antagonistas. Es quizás tiempo de reconocer en la hipocresia, no sólo un mezquino defecto contingente del hombre, sino el desgarramiento profundo de un mundo adherido a la vez a los filósofos y a los profetas [E. Levinas, Totalité et Infini, p. XII].

\section{La diferencia greco-judía}

Seguramente lo que determina la singularidad y la importancia de la obra de Levinas en el pensamiento contemporáneo es su potente explicación del problema de la diferencia entre los dos origenes que, irreductibles el uno al otro, constituyen o construyen la civilización occidental: el logos griego, por un lado, el intelectualismo de una razón cuya mayor expresión es la filosofía y cuyo destino más íntimo es la autonomía, y por otro lado la tradición judía de la Biblia y el Talmud, que busca la humanidad del hombre en el imperativo radical de la justicia proclamado por la palabra profética en el horizonte mesiánico. Diferencia, decimos, irreductible, histórica e intelectualmente, lo cual desautoriza de entrada todo intento de síntesis, totalización y «asimilación»: algo así sólo sería posible, o aparentemente posible, mediante la reducción de un origen a otro. Pero diferencia irreductible también, por otra parte, a la distancia oposicional entre posicio- 
nes antagónicas e incompatibles. Desde luego lo que está en juego no es un residuo de la disputa entre Ilustración y Religión. Es conocida, y a ello volveremos aquí, la punta antiteológica y antidogmática de la obra de Levinas. No nos precipitemos por otra parte a decir "diálogo", una palabra que no sería neutra puesto que al menos en su sentido enfático y marcado pertenece a la lógica del origen griego y a la dinámica interna de la filosofía. Se trata más bien de una explicación, exigida por ambas partes, entre tradiciones originales diferentes, cuya resistencia recíproca no puede dar lugar más que a una relación de traducción; y como toda traducción, posible sólo en el horizonte de una última intraducibilidad, de una imborrable dualidad de lenguas en cada discurso, en cada lado de la relación. Traducción también en el sentido de una "negociación», una relación de fuerza entre fuerzas y recursos que escapa al puro intercambio dialéctico de ideas. La metáfora - si lo es- de la negociación se impone aquí por otra parte tanto más porque este pensamiento es, entre otras cosas, una profunda meditación de la violencia y la guerra.

Esta singularidad, o lo inédito de la profundidad con que se produce en Levinas la explicación de la dualidad greco-judía no debería atenuarse con el recuerdo de antecedentes ciertamente memorables de esa tentativa: lejanamente el del por Levinas muy admirado Maimónides, y más próximos y aquí más relevantes, los del último Hermann Cohen —que quiso articular la ética kantiana y el judaísmo en el marco de una renovación del tema de la religión en los límites de la razón-, de Martin Buber - con cuya filosofía del diálogo y del Yo-Tú sin embargo Levinas polemiza en puntos esenciales- (nota 1 sobre Buber y también referencia a Cohen y Maimónides), y sobre todo de Franz Rosenzweig. De éste Totalité et Infini dice que su obra Stern der Erlösung «está demasiado presente para ser citada». ${ }^{1}$ La declaración parece excesiva: el estilo analítico y expositivo, así como las articulaciones fundamentales de Totalité et Infini no dejan ver esa presencia presuntamente ilimitada. Por otro lado, el problema esencial para el judío alemán había sido, más que la diferencia grecojudía, la dualidad del judaísmo y el cristianismo. Y ello a partir de una puesta en crisis de la cultura clásica alemana sintetizada en Hegel y Goethe. Es quizás la crítica del hegelianismo, como crítica de la filosofía de la totalidad - junto con el tema de la creación- lo que cabe reconocer como más eficaz "presencia» de Rosenzweig en el pensamiento de Levinas. En cualquier caso, la comparación con tentativas precedentes -relacionables más o menos directamente con los textos de Levinas- confirmaría la originalidad con que éste acoge una problemática más vieja que la historia del cristianismo. En algún lugar Levinas apunta a lo que está en la base de su diferencia respecto a anteriores filósofos-judíos: la experiencia histórica del fracaso ético-político del racionalismo europeo, y más precisamente, la experiencia del nazismo y la shoah en el corazón de 
una cultura determinada en buena parte por las tensiones internas del idealismo alemán. ${ }^{2}$

Ahora bien, los textos más decisivos de Levinas muestran que la difícil y necesaria diferencia entre el logos filosófico griego y la palabra profética judía constituye algo más que un problema con el que este pensamiento se explica originalmente. Es también un problema o una dificultad para la interpretación de ese pensamiento: no está claro, en efecto, el estatuto del discurso en que tiene lugar esa explicación. ¿Cómo leerlo? ¿Cómo leerlo si se ha de evitar el rechazo alérgico que sin duda experimentaría ante él un racionalismo sin oído para el enigma? Pero también, ¿cómo leerlo si se quiere hacer justicia a su pretensión de ser un discurso rigurosamente filosófico, que se legitima en la razón y en la experiencia?

Nuestro problema al mismo tiempo se precisa y se complica a la vista de una escisión que muy aparentemente parte en dos el corpus textual de Levinas: por un lado, los escritos que más o menos problemáticamente se presentan en cualquier caso como filosóficos -especialmente Totalité et Infini (1961), Autrement qu'être ou au delà de l'essence (1974) y De Dieu qui vient à l'idée (1982)-; por otro lado, los ensayos por así decirlo militantemente judíos reunidos en Difficile Liberté (1963) y sobre todo la serie de lecturas talmúdicas: Quatre lectures talmudiques (1967), Du sacré au saint (1977), Au delà du verset (1982) y À lheure des nations (1988). Decimos que esta división al menos exteriormente clara de la obra de Levinas ${ }^{3}$ precisa el problema en la medida en que con ello parece objetivarse una distinción, una distribución entre las dos inspiraciones cuya diferencia y cuya relación piensa y practica el pensamiento de Levinas. Pero esa disposición es también un motivo para una agudización del problema en la medida en que plantea muy materialmente la necesidad de seguir el intercambio --más o menos abierto, y esa inseguridad es característica- entre los dos géneros discursivos practicados por Levinas.

Para orientarse en el problema de la distinción y el intercambio entre los dos géneros - desde cada uno de los cuales se piensa la diferencia greco-judia - es interesante notar que los escritos talmúdicos de Levinas son relativamente tardíos en la biografía intelectual de éste. En cualquier caso todos ellos se publicaron con posterioridad a Totalité et Infini, la primera y en cierto modo la única obra en que Levinas expone de forma sistemática su pensamiento filosófico. Además, las premisas intelectuales y las técnicas de análisis y exposición de ese libro —on el que Levinas obtuvo el comienzo de un reconocimiento lento pero irreversible en la filosofía francesa y europea más allá de los medios fenomenológicos- remiten a una amplia trayectoria anterior inequívocamente filosófica: recepción muy precoz de la fenomenología husserliana y de la filosofía de la existencia heideggeriana (La théorie de l'intuition dans la phénoménologie de Hussenl, 1931; En decouvrant l'existence avec Husserl et Heidegger, 1949, que contie- 
ne algunos ensayos publicados previamente antes de la Guerra); primera tematización del motivo platónico del Bien más allá del ser y elaboración de una ontología pluralista; filosofía del existente como "hipóstasis» que se emancipa del neutro mero «existir» o anónimo «hay», y la alteridad del tiempo y de la diferencia sexual (De l'existence à l'existant, 1947; Le temps et l'autre, 1948). En cuanto a los ensayos sobre el judaísmo que recoge Difficile Liberté en 1963, pero que habían aparecido previamente a partir de 1945, hay que tener en cuenta que son en su mayor parte comentarios de carácter político y cultural, y que se sitúan de hecho abiertamente en un contexto apologético, pedagógico y polémico. Su explícito objetivo es darle o restituirle al judaísmo una dignidad intelectual más allá de lo patético y del particularismo folklórico, mostrar su sentido de universalidad, defenderlo de su tentación de sasimilación» al mundo moderno, y reivindicarlo en fin, como «religión para adultos», frente al drama cristiano de una salvación que suspende la moral. ${ }^{4}$ Pero ahí todavía no llega a expresarse una elaboración teórica del judaísmo como aventura intelectual que requiera, ante la filosofía dominante en Occidente, explicarse precisamente en su diferencia con respecto a la tradición griega. Esa elaboración sólo será posible a partir de un estudio sistemático de la verdadera fuente del judaísmo: el Talmud. Ahora bien, con la notable excepción de un atormentado e inseguro comentario sobre el mesianismo fechado en $1961,{ }^{5}$ los ensayos de Difficile Liberté se mantienen en un nivel previo al estudio del talmudismo. Habitualmente una formación completa en el talmudismo exige la dedidación de toda una vida. Levinas se introduce sin embargo en ese mundo muy tardíamente, empieza a aprenderlo a partir de la Liberación $^{6}$ y, como hemos visto, sólo a partir de los sesenta dicta sus confercncias talmúdicas.

Las precisiones cronológicas anteriores no pretenden documentar algo así como una partición de la obra de Levinas, que habría sido puramente filosófica y fiel a la génesis griega hasta la publicación de Totalité et Infini, y que a partir de entonces incorporaría como componente eficaz el talmudismo planteando así, en el interior de su propio discurso, la dualidad greco-judía. Lo cierto es que en aquella obra es ya visible y efectiva la duplicidad de origenes y de lenguas. De hecho, y como vamos a ver, desde sus primeras páginas Totalité et Infini invoca lo que llama el "fenómeno" de la escatología mesiánica, y a título de «situación" que una fundamentación subrayadamente filosófica de la ética ha de tener en cuenta. Pero la lengua dominante en el discurso de esa obra es la lengua dominante de la filosofía occidental, el lenguaje de la ontología fundado en Grecia y "aprendido" por Levinas en la fenomenología de Husserl y Heidegger.

Se trata, en lo que sigue, en primer lugar, de confirmar esta hipótesis hermenéutica: que Totalité et Infini (TT), en su intención más profunda y en la articulación de su proyecto, pretende resolver la tensión greco-judía o 
filosófico-mesiánica en un lenguaje filosófico. La atención fiel al sistema de esa intención no impedirá, en un segundo momento, el reconocimiento de las aporías que afectan internamente a ese proyecto. Se pondrá así en evidencia una contradicción, insuficientemente pensada a lo largo de todo el libro, entre su condición ontológica y su programa heterológico. En tercer lugar se intentará mostrar que una implícita respuesta a esas aporías está a su vez en la base del desplazamiento que lleva a Levinas a volver a pensar el estatuto del lenguaje filosófico en su scgunda obra fundamental, Autrement qu'être ou au delà de l'essence.

\section{El lenguaje filosófico de la ética escatológica}

La tan citada primera frase de Totalité et Infini deja ver con claridad tras su retórica irónica («Aceptaremos fácilmente que es cuestión de gran importancia saber si la moral no es una farsa") la motivación original y el horizonte del libro: la necesidad de una moral sin ilusiones, la búsqueda de una ética lúcida.

Implícitamente, pues, pero indudablemente, Levinas reconoce de entrada un conflicto, un problema o una dificultad para conciliar los ideales del conocimiento y los de la moral. Conflicto viejo como el pensamiento occidental, pero al que las tensiones internas en el proceso de maduración del racionalismo moderno hasta Kant y Hegel, y sobre todo la experiencia histórica del fracaso civilizatorio de ese racionalismo a lo largo del siglo $\mathrm{xx}$, han llevado a un nivel inédito de radicalidad. Hasta tal punto que lo que estaría en juego, tras el dilema entre saber y moral, es la omnipresencia de la guerra o la posibilidad de la paz.

En principio el testimonio de la historia parece aportar pruebas irrefutables de la realidad de la guerra como horizonte permanente de la experiencia humana. Ahora bien, la secuencia de este discurso llevará con plena coherencia a poner en cuestión el valor de la historia. La ética levinasiana del rostro es expresamente incompatible con toda filosofía de la historia, con toda pretensión de que haya una racionalidad, un sentido y una justicia en la historia. Lo que se llama el juicio de la historia es en cada caso una interpretación de los supervivientes que olvidan la verdad propia de cada instante, la significación de cada momento que brilla con luz propia: "sin contexto", $Y$ es el punto de vista de la historia o de la historiografía el que cita, por así decirlo, Levinas, para indicar que en primera instancia el realismo del conocimiento se ofrece como el reconocimiento de la necesidad de la guerra. De ahí se derivaría una secundarización de la moral, o una desilusión de su primaria vocación pura y utópica, y su sustitución por un recurso racional ajustado a las leyes de la guerra: la política. El párrafo que sigue cita o reproduce el punto de vista de la historia, de la política y de la guerra: 
La lucidez - apertura del espíritu sobre lo verdadero- tno consiste acaso en entrever la posibilidad permanente de la guerra? El estado de guerra suspende la moral; despoja a las instituciones y obligaciones eternas de su eternidad y, por lo tanto, anula en lo provisorio los imperativos incondicionales. Proyecta su sombra por anticipado sobre los actos de los hombres. La guerra no se sitúa solamente como la más grande entre las pruebas que vive la moral. La convierte en irrisoria. El arte de prever y ganar por todos los medios la guerra -la política- se impone, en virtud de ello, como el ejercicio mismo de la razón. La política se opone a la moral como la filosofía a la ingenuidad [TI, p. IX; trad. p. 47].

El paso a la filosofía seria, pues, el paso a un discurso de la guerra: no un discurso que tenga como objeto o como tema la guerra, sino un discurso coherente con la experiencia del ser como guerra. El vínculo de guerra y ser no sería una metáfora de algún oscuro presocrático, sino una evidencia o patencia típicamente filosófica. En la guerra «la realidad desgarra las palabras y las imágenes que la disimulan para imponerse en su desnudez y su dureza. Dura realidad (iesto suena como un pleonasmol), dura lección de las cosas, la guerra se presenta como la experiencia pura del ser puro, en el momento mismo de su fulgor en el que se queman los decorados de la ilusión" ( $T I$, p. IX; trad. p. 47).

Levinas tiene a la vista los rasgos de la guerra moderna, si bien ésta no hace sino poner de manifiesto la esencia virtual de toda guerra. Ante todo, la experiencia de la guerra se presenta como experiencia del ser en la medida en que aquélla se da como el acontecimiento ontológico de una "puesta en movimiento de los seres", como una "movilización de los absolutos». El significado esencial de esa violencia no es su aspecto físico de anulación y herida de las personas, sino el que éstas traicionan su propia sustancia hasta hacerse incapaces de cualquier acción. Esa movilización es universal y eso quiere decir también que afecta a quienes la ponen en marcha: «Como en la guerra moderna, en toda guerra las armas se vuelven contra quien las detenta. Es imposible alejarse del orden que ella instaura. Nada queda fuera».

Pero ese es «sólo» el testimonio de la historia. La limitación, la parcialidad de ésta se acusa cuando Levinas precisa en qué determinado concepto, en qué determinado régimen intelectual ha pensado la civilización occidental nacida en Grecia la experiencia del pólemos padre de todas las cosas. El concepto de totalidad «que domina la filosofía occidental» no fija la expcriencia pura del ser puro, sino sólo «la faz del ser que se muestra en la guerra». Como la guerra moviliza y desarraiga hasta destruirlos a los individuos, así el concepto de totalidad proyecta un tipo de inteligibilidad (el dominante en la filosofía occidental) en el que la unicidad del individuo y del instante se subordinan al todo como partes sin sentido propio.

En cstas condiciones no sería posible la conciencia moral sin autoengaño. Si esas condiciones fueran las de toda experiencia del ser, entonces 
la moral sólo sería ilusión subjetiva vana. La moral depende de la posibilidad de la paz. Y la certeza de la paz no es tal si se funda en una antítesis de la guerra. La paz que resulta de la guerra, del fin o de la suspensión de la guerra, seria el caso de esa paz puramente antitética a la guerra. Se requiere otra relación con el ser: "La paz de los imperios salidos de la guerra se funda en la guerra. No devuelve a los seres alienados su identidad perdida. Para ello es necesario una relación original y originaria con el ser» (TI, p. X; trad. p. 48).

Ahora bien, y aquí se empieza a ver el problema apuntado de la dualidad greco-judía que determina el pensamiento de Levinas, esa nueva, original y originaria relación con el ser que puede fundar la certeza de la paz no se registra, al menos no directamente, en la filosofía. La moral sólo podrá emanciparse de la política y de la guerra «históricamente", "cuando la escatología de la paz mesiánica se sobreponga a la ontología de la guerra» (TI, p. X; trad. p. 48). En primera instancia, esa invocación escatológica no sólo es ajena a la filosofía, sino que suscita desconfianza en los filósofos. De hecho éstos utilizan en su propio discurso aquella idea de paz "deduciéndola» de una razón política cuyo elemento natural es la guerra. Pero lo escatológico no tiene lugar en la filosofía. Para los filósofos la escatología forma parte de lo que se llama "opinión": «Adivinación subjetiva y arbitraria del futuro, fruto de una revelación sin evidencias, tributaria de la fe, la escatología surge para ellos con toda naturalidad de la Opinión» ( $T I$, p. X; trad. modif. p. 48). Sin embargo, frente a tal reducción y exclusión de la idca escatológica de la paz mesiánica, para Levinas no se trata de hacerle reconocer su derecho a la ciudadanía en el pensamiento asimilándolo a una evidencia filosófica. Es otro el juego que le asigna Levinas al "extraordinario fenómeno de la escatología profética", precisamente el de lo que está fuera del orden, y ante todo fuera del orden de las cvidencias filosóficas que miran siempre, por así decirlo, a la faz del ser que se muestra como guerra.

Dos precisiones se imponen aquí. La primera es una llamada de atención sobre el hecho de que, a pesar de las apariencias, Levinas no rechaza simplemente la pertinencia y el alcance de lo escatológico en el pensamiento filosófico: lo que en realidad niega es que aquello se incorpore o se asimile a las "evidencias filosóficas". En la diferencia entre las evidencias filosóficas y el discurso filosófico se aloja la posibilidad de una ética como filosofía primera, no sometida, pues, a la política y a la ontología de la guerra. La segunda precisión concierne directamente al estatuto del discurso filosófico de la obra. Se trata de que el fenómeno escatológico, en el que tendría su verdadero origen la certeza de paz y la posibilidad de moral, no sólo no pertenece al orden de las evidencias filosóficas, sino que tampoco puede acompletarlo». Esa perspectiva de síntesis o de complcmentariedad es la de las religiones y las teologías. Se advierte aquí que, 
contra lo que pudiera parecer, la de Levinas no es una filosofía teológica ni religiosa. Religión ${ }^{7}$ y teología pertenecerían al mismo orden de las «evidencias filosóficas" que pretenden completar. Su «aportación» característi$\mathrm{ca}-\mathrm{y}$ en ello se manifiesta la coherencia con la filosofía de la totalidad o de la guerra - es la de introducir una orientación teleológica en la historia. Las religiones y las teologías son filosofía de la historia. Y la frase puede invertirse. En cualquier caso es claro que el discurso que Levinas busca para hacer justicia a una ética fuera del horizonte de la guerra no encuentra ni su modelo ni su cómplice en la religión ni en la teología. Se busca o se requiere una relación con el ser más allá de la totalidad, y eso quiere decir aquí más allá del sentido teleológico de una historia. La "lógica» de esa nueva relación no es la de llenar un vacío o completar una falta, sino la de un exceso, una excedencia exterior al sistema que conforman la evidencia filosófica, la faz del ser como guerra y cl concepto de totalidad.

Así como el concepto rector en la filosofía dominante en Occidente es el de totalidad, el concepto - filosófico también, incluso en un sentido más primordial - que permite pensar aquella excedencia o trascendencia respecto a la totalidad es la idea de infinito. En principio ésta se presenta -y ya por su gramática- como un concepto negativo, como negación de lo finito. Si así fuera, la exccdencia respecto a la totalidad que pretende pensar el concepto de infinito quedaría reducida a un vacio, dependiente a su vez del plenum finito. La interpretación del infinito como concepto negativo supone el primado -lógico y ontológico- de lo finito. Lo cierto es que la racionalidad filosófica dominante, determinada en esto muy señaladamente por su ancestro griego, ha tendido a pensar así lo infinito. El infinito positivo, la perfección como infinitud, que Levinas contrapone sistemáticamente al concepto de totalidad, le aparece a aquella tradición como una contradicción. ${ }^{8}$

Ahora bien - volviendo al hilo del prefacio de Totalité et Infini- el horizonte de la paz escatológica requerido por una ética no dependiente de la guerra sólo es pensable en la medida en que lo infinito se refleje en la historia y la experiencia. En rigor, lo pensable, y más precisamente, lo enunciable en un discurso filosófico es un «reflejo» de lo infinito "en el interior" de la historia: una dislocación o desestabilización de la experiencia ordenada al ser que se muestra en la guerra y la política. Así, la perspectiva escatológica de la paz no remite a la consumación de los tiempos y al futuro apocalíptico: su ámbito es el de una relación original con el ser que no supedita los entes a la neutralidad del conjunto de la realidad o totalidad. Esto quiere decir: relación con el ser que devuelve a los entes su significación propia - significación sin contexto-, y su capacidad de palabra. Al silencio de las guerras o de la paz armada de los imperios, se contraponen en un mismo movimiento, la paz escatológica, el derecho de expresión de los entes por excelencia que son los hablantes, y la visión 
moral. Esta "visión», esta "óptica» - profundamente ajena a la objetivación y a la luz que parecen consustanciales a la dialéctica de la mirada propiamente dicha - constituye el eje de la obra. Y en esta primera explicación del objetivo propuesto - anunciado implícitamente en el comentario al dictum que condena la perspectiva moral a ingenuidad - concluye la reflexión central del prefacio: dependiente de una visión escatológica --necesaria para salir del sistema de la ontología de la guerra-, la visión moral se presta a una descripción en la medida en que entra en la historia y en la experiencia, por más que ello sea al modo de la ruptura, la dislocación y el desorden.

La enunciación de un tal programa filosófico, que ha de leer en el intenior de la experiencia y de la historia un "más allá" de la una y de la otra, no puede dejar de suscitar dificultades y resistencias, sin embargo. ¿Cómo replicar a lo que sería la crítica filosófica previsible a una ética inquieta por la escatología? Aunque la razón filosófica dominante o típica aceptara que una paz perfecta sólo puede ser correlato de una visión escatológica y una palabra profética, aquélla podrá siempre volver a insistir en la evidencia, en la «irrefutable evidencia» del reinado de la totalidad y la guerra en el ser. Sc dirá: una cosa es el Bien y la paz perfecta - a lo que cree poder aspirar ilusoriamente una subjetividad sin arraigo ontológico-, otra cosa es la Verdad, objeto del conocimiento, la representación objetiva y la evidencia.

En una especie de paréntesis, y antes de responder al problema de cómo "traducir» la escatología a lenguaje filosófico sin traicionar la irreductibilidad de uno a otro, Levinas apela a una especie de respuesta práctica, o más bien fáctica. Se trata del «hecho» de una civilización, la nuestra, que mantiene "hipócritamente» dos fidelidades antagónicas -antagónicas en la medida en que ambas aspiran al primado sobre la otra-, al Bien y a la Verdad. Esa hipocresía no es un engaño, es un "desgarramiento". De ese desgarramiento entre el filósofo y el profeta tiene que poder dar cuenta el filósofo moral si es que éste ha de asumir la perspectiva de la posibilidad de la paz.

El problema es que la filosofía buscada, o necesaria, no puede saltar simplemente fuera de la evidencia filosófica - lo que sería un riesgo permanente de arbitrariedad-, ni puede "continuarla". Algo tiene que «rompers la evidencia de la guerra, pero como una ruptura interna, reconocible en la evidencia. Con una prudencia notable en el léxico, Levinas no llama a ese algo "fenómenon: lo llama, como subrayando su carácter de coyuntura significativa, más que de objetividad plena, situación. Esa situación sería la manifestación de la trascendencia en el rostro del otro.

Pero para el filósofo, la experiencia de la guerra y de la totalidad ino coincide acaso con la experiencia y la evidencia a secas? ¿Y la filosoffa misma no se define, al fin de cuentas, como una tentativa de vivir en la evidencia, al oponerse a la opinión del prójimo, a las ilusiones y a la fantasía de su propia subjetividad? A 
menos que la evidencia filosófica remita por sí misma a una situación que no pueda ya expresarse en las categorias de la totalidad. A menos que el no-saber en el que comienza el saber filosófico, no coincida con la nada a secas, sino sólo con la nada de los objetos. Sin sustituir la filosofía por la escatología, sin "demostrar" filosóficamente las "verdades" escatologicas: se puede ascender a partir de la experiencia de la totalidad a una situación en la que la totalidad se quiebra cuando esta situación condiciona la totalidad misma. Tal situación es el resplandor de la exterioridad o de la trascendencia en el rostro del otro [ $T I$, pp. XII-XIII; trad. pp. 50-51].

Al insistir en que el concepto de esa situación, de esa trascendencia, esto es, el concepto de infinito, no implica retroceder a algúm tipo de dogmatismo, Levinas anuncia la proximidad de su proyecto al ideal criticista y al método trascendental. Aun sin comprometerse en el idealismo trascendental, aquel método, madurado en la práctica fenomenológica, habría prefigurado en otro terreno, la «manera» reivindicada aquí de remontarse a un orden previo a la representación y la evidencia.

La filosofía que Levinas llama recurrentemente "dominante» objetaría sin duda que la idea de infinito, o la acogida de lo infinito en un espíritu finito, implica violencia a la autonomía. Y la filosofía, tanto más en su momento de madurez reflexiva y crítica, se identifica con el ideal de la autonomia. Es cierto que Levinas no recurre, o apenas, al término sheteronomía» al menos en Totalité et Infini. ${ }^{9}$ Pero es claro en cualquier caso que su ideal de filosofía y de razón no es la autonomía. Y sin embargo su recurso a la idea de infinito que desborda al pensamiento y que obliga al pensamiento a salir de sí al exterior no tiene nada que ver con la «opinión» que la filosofía critica como heteronomía y sometimiento. En efecto, la opinión "se desvanece como el viento cuando el pensamiento la toca"; en cambio, en la idea de infinito, lo exterior al pensamiento se mantiene incólume, siempre exterior. Da así, si no el modelo, sí la condición del pensamiento objetivo, esto es, constituido como verdadero por la razón:

Condición de toda opinión (la idea de lo infinito), es también condición de toda verdad objetiva. La idea de lo infinito es el espínitu antes de presentarse a la distinción de lo que descubre por sí mismo y de lo que recibe de la opinión $\left[T T_{1}\right.$ P. XIII; trad. p. 51].

La siguiente puntualización sobre el estatuto filosófico del discurso de la obra se mueve también en un contexto polémico con el kantismo. Tras anunciar la eficacia del método trascendental para una ética libre de las "evidencias" filosóficas - dependientes siempre de la ontología de la guema, de la prudencia política y de la filosofía de la historia-, Levinas ha indicado su resistencia al ideal de la autonomía de la razón. Ese distanciamiento se precisa como un peculiar empirismo. En un sentido, la experien- 
cia, como apertura y desarrollo de la consciencia, pertenece al sistema inmanente de la totalidad. Pero en otro sentido, que es prioritario, la experiencia "por excelencia" significa justamente relación con lo absolutamente otro, y así, relación con lo infinito.

Una última delimitación de la visión ética suscitada por el fenómeno escatológico concierne al problema de la subjetividad. En la caracterización del orden dominado por la totalidad y la guerra Levinas había subrayado la anulación del individuo en una movilización que alicna a los entes su ipseidad. Frente a lo cual la filosofía de lo infinito puede presentarse como una defensa de la subjetividad. Frente al sistema por antonomasia de la totalidad que es el hegelianismo, dos pensadores ambos importantes en la formación de Levinas, se han destacado por la eficacia de su reivindicación del individuo y el existente: Kierkegaard y Heidegger. Sin embargo, la subjetividad que surge o que resalta en el curso de la filosofía de la infinitud, y a pesar de estratégicas asociaciones, no es ni la apasionada protesta del yo kierkegaardiano contra el Sistema, ni tampoco la libertad finita del Dasein heideggeriano en su angustia ante la muerte. Aquellos antihegelianos pretenden liberar la subjetividad o la existencia del sistema teleológico de la historia; de hecho permanecen ligados a un «subjetivismo impotente y desligado del ser» (cf. $T I$, p. XIV; trad. p. 52). La idea de infinito como pensamiento moral no arranca a la subjetividad ni del ser ni de la historia: la constituye en responsabilidad ante el rostro del otro.

A decir verdad, si bien según el orden del discurso y según el orden de las cosas la idea de infinito es fundante respecto a esa subjetividad ética, ésta no se limita a ser un efecto de lo infinito. Tampoco puede decirse que la idea de lo infinito en la subjetividad «refleje» lo infinito. La producción de la idea de infinito, o el modo de estar ésta puesta en la subjetividad, tiene lugar en la relación esencialmente inadecuada entre la subjetividad y la exterioridad que aquélla desea desde su más profunda raíz. La esencial inadecuación que rige, más allá de la relación intencional objetivante, la vida de la subjetividad en su movimiento de trascendencia a lo otro que ella, y especialmente en la trascendencia del rostro del otro, tiene su condición de posibilidad en la idea de infinito. Así, esta metafísica de lo infinito, lejos de toda especulación teo-lógica, se desarrolla como descripción de la dinámica de una subjetividad separada que acoge lo que en rigor no puede contener:

Lo infinito no es primero para revelarse después. Su infinición se produce como revelación, como una puesta en mí de su idea. La infinición se produce en el hecho inverosímil en el que un ser separado, fijado en su identidad, el Mismo, el Yo, contiene sin embargo en sí lo que no puede contener, ni recibir por la sola virtud de su identidad. La subjetividad realiza estas exigencias imposibles: el hecho asombroso de contener más de lo que es pasible contener. Este libro presentará la subjetividad recibiendo al Otro, como hospitalidad. En ella se lleva a cabo la idea de lo infinito. La intencionalidad en la que el pensamiento sigue siendo adecuación 
al objeto, no define la consciencia en su nivel fundamental. Todo saber en tanto que intencionalidad supone ya la idea de lo infinito, la inadecuación por excelencia [TI, p. XV; trad. pp. 52-53].

Así, pues, la idea de infinito como tal $-\mathrm{c}$ su estructura formal de desbordamiento del continente por el contenido, y en su estructura concreta de trascendencia del rostro a la evidencia y los poderes del yo- no es una representación, una idea teórica, o un "pensamiento".

No es tampoco, sin embargo, actividad, encarnación de un pensamiento en la praxis. En este contexto teoría y praxis se sitúan en un mismo plano, como dos modos paralelos de la trascendencia metafísica. Esa "confusión aparente» - ni la jerarquía ni la solidaridad, esquemas con que la tradición filosófica ha presentado hasta ahora la relación entre el saber y la acción - es una de las tesis del libro (cf. $T I$, p. XVI; trad. p. 55). Los temas típicos de esta filosofia de lo infinito no son, pues, ni los objetos del pensamiento (ni el pensamiento en su dinámica interna), ni los actos de un sujeto encarnado y práctico: son más bien acontecimientos de la subjetividad, o "dramas" en el sentido del Nietzsche de El caso Wagner (al que remite Levinas en este contexto).

La irreductibilidad de esos acontecimientos a la claridad tendencial de la representación y la acción se subraya por el carảcter esencialmente noctumo de aquéllos. En esto se anuncia uno de los motivos esenciales del discurso filosófico levinasiano en su diferencia respecto a la tendencia dominante en el pensamiento occidental: la critica de la luz, la crítica de la violencia de la luz. ${ }^{10}$ De esa violencia participaría especialmente la idea heideggeriana de la verdad como desvelamiento que resulta de una comprensión o proyección. Al desvelamiento Levinas opondrá regularmente la revelación, la manifestación del rostro que se presenta por sí mismo, o se expresa, sin someterse a la violencia de un elemento neutro luminoso.

El respeto a los acontecimientos nocturnos que constituyen la subjetividad fundada en la idea de infinito no es, sin embargo, el principio de un irracionalismo. ${ }^{11}$ Se repite de nuevo el gesto general de autoexplicación en este sentido que recorre las páginas del prefacio de Totalité et Infini. Más arriba, la apelación al horizonte de la paz mesiánica de la ética llevaba a una interpretación filosófica de la experiencia y no a un dogmatismo religioso o teológico. Ahora Levinas subraya que la significación de los acontecimientos no es irracional: "La significación a la que, en esta obra, la deducción fenomenológica remite el pensamiento teórico sobre el ser y la exposición panorámica del ser mismo, no es irracional. La aspiración a la exterioridad radical, invocada por esta razón metafísica, el respeto de esta exterioridad metafísica que es necesario, ante todo, "dejar ser", constituye la verdad. Ella impulsa este trabajo y atestigua su fidelidad al intelectualismo de la razón» (TI, p. XVII; trad. pp. 54-55). 
La tensión entre el respeto a la esencia nocturna de la subjetividad y la fidelidad al intelectualismo de la razón se encuentra, pues, en el centro metódico de Totalité et Infini; tensión que refleja a su vez la dualidad greco-judía, o filosófico-escatológica que marca la singularidad, y la importancia, de este discurso. Esta situación se precisa de manera ejemplar en relación con la fenomenología: por un lado, la subjetividad que acoge el infinito o el rostro, no es fenomenología, fosforescencia o luz; pero por otro lado «la presentación y el desarrollo de las nociones empleadas deben todo al método fenomenológicon. Es así, en cualquier caso, como Levinas propone el sentido y la marcha general de su proyecto. ${ }^{12}$ Debemos preguntamos ahora, por nuestra parte, acerca de la legitimidad o de las dificultades de esta tentativa de traducción filosófica del fenómeno escatológico, al que remitió previamente la necesidad de una certeza de paz como horizonte de la ética.

\section{La condición ontológica del pensamiento heterológico}

La estructura de Totalité et Infini revela una intención sistemática que hay que calificar de onto-lógica - a pesar de la declaración levinasiana del primado de la metafísica sobre la ontología-, intención que queda violentamente relegada cuando se interpreta el pensamiento de esa obra como una moral subjetiva y utópica animada por la patética del rostro en un lenguaje finalmente religioso. La idea de la ética como filosofia primera en Totalidad et Infinito sólo cobra su sentido pleno y su posible legitimidad en un cuadro teórico cuyo rango ontológico hay que empezar por reconocer.

La primera sección del libro, "Lo Mismo y lo Otro", expone las bases de una ontología heterológica, la división del ser en lo Mismo y lo Otro como condición conceptual para pensar la experiencia de la trascendencia. El pensamiento heterológico justifica la trascendencia —en contra de la tendencia dominante de la filosofía occidental, pero manteniéndose en el marco del lenguaje de ésta- estableciendo el primado de la idea de infinito sobre el concepto de totalidad. Sólo la idea de infinito permite pensar el intervalo o la relación trascendente entre lo Mismo y lo Otro, entre el yo y lo Absoluto. El concepto de totalidad, al sumar lo Mismo y lo Otro, reduce de hecho el segundo al primero. La segunda sección, "Interioridad y Economía», es una ontología de la existencia cotidiana, próxima por sus temas a la hermenétutica heideggeriana del ser-en-el-mundo y en general a la fenomenología de la experiencia del Lebenswelt. En el orden argumental del libro, esta descripción de la existencia cotidiana insiste en la vocación de plenitud, satisfacción y autonomía de un yo que, sólo así, en tanto feliz y separado, podrá desear al otro sin necesitarlo, fuera, pues, de la lógica de la totalidad. La tercera sección, "El rostro y la exterioridad", articula el núcleo propiamente ético de la obra: en la relación con el rostro del otro 
-expresión de lo que se presenta y se revela por sí mismo, desde más allá del horizonte de mi comprensión o poder de desvelamiento- se concreta como respeto ético absoluto la relación metafísica inscrita en la idea de infinito. La cuarta sección, bajo el título "Más allá del rostro", profundiza en la experiencia del éros y de la fecundidad como lugar privilegiado de realización de lo que parece una contradicción pero que viene exigido por este discurso: la infinitud de un ser temporal.

A pesar de su continuo debate con las tendencias filosóficas dominantes en un Occidente marcado intelectualmente ante todo por Grecia, esos cuatro movimientos mantienen de principio a fin un lenguaje filosófico, y más precisamente el lenguaje legado por la ontología griega y desplegado por el racionalismo europeo hasta Husserl. Si nos atenemos al cuerpo del libro - las cuatro secciones resumidas, prescindiendo del prefacio y de las conclusiones- no encontraremos una tematización abierta de la diferencia greco-judía. El último párrafo de la cuarta parte parece confinmar esa exclusión del problema: ante las dificultades que suscita la idea de un tiempo infinito, Levinas evoca alli fugazmente el tiempo mesiánico; ahora bien, inmediatamente afirma que ese problema «desborda el marco de este libro» (TI, p. 261; trad. p. 292). Ahora bien, hemos visto que el propio Levinas reconocía abiertamente en el prefacio la irreductibilidad de la experiencia escatológica, abierta a la certeza de una paz perfecta, como condición necesaria de una ética libre de las leyes de excepción de la guerra y de las estrategias para-bélicas de la política. Implícitamente, pues, el discurso de Levinas supone, o más bien realiza, una "traducción" de ese elemento judio a la lengua griega, al medium mismo de la universalidad que es la ontología filosófica. Lo que señala en el discurso levinasiano de Totalité et Infini su carácter de traducción es justamente aquello que fundamenta su apartamiento respecto a las tesis dominantes en la filosofía occidental: el pensamiento heterológico, la trascendencia irreversible de lo Otro. Hay que reflexionar, sin embargo, sobre el límite de esa traducción, - sobre la capacidad de resistencia de la ontología griega de lo Mismo frente a la metafísica judía de lo Otro. En esto, el largo y profundo estudio de Derrida «Metafísica y violencia. Ensayo sobre el pensamiento de Levinas " ${ }^{13}$ ha sido determinante de la literatura sobre Levinas, y sin duda también del pensamiento posterior del propio Levinas. ${ }^{14}$

Derrida empieza su ensayo precisando el alcance de la cuestión que Levinas plantea al conjunto de la filosofía occidental. El poder de dislocación y desestabilización de la filosofía clásica que tendría la empresa intelectual de Levinas se explica porque aquélla se sitúa en la misma profundidad con que las tres grandes voces de Hegel, Husserl y Heidegger habían "repetido" la necesidad de aquella tradición. Levinas pone en cuestión los tres motivos constitutivos de dicha triple repetición de la filosofía en su forma «dominante»: reafirmación del origen griego sin connotación histo- 
ricista, reducción de la metafísica, y subordinación de la ética. Ya en ese primer momento de situar en tal contexto polémico el programa levinasiano, $y$ al pretender que aquellos tres motivos «Predeterminarían [...] la totalidad del $\log o s$ y de la situación histórico-filosófico mundial", Derrida avanza implícitamente su uobjeción" principal: "Ninguna filosofia podría conmoverlos (los tres motivos mencionados) sin comenzar por someterse a ellos o sin acabar por destruirse ella misma como lenguaje filosóficon. ${ }^{15}$ Es claro, sin embargo, que Levinas pretende conmover aquellos tres motivos sin someterse a ellos, y hacerlo desde un lenguaje filosófico. Acabamos de precisarlo manteniéndonos por lo pronto en la literalidad del texto de Levinas: el pensamiento heterológico se expone como una ontología, o también, la ética abierta a (o por) la paz escatológica debe constituirse como una lectura filosófica de la experiencia. Sigamos, al menos parcialmente, el hilo de la argumentación de Derrida como "defensa" de la ontología greco-europea frente a la tentativa levinasiana de resistirse a la dominación de la filosofía "dominante" (o filosofía de lo Mismo) en o a través del lenguaje de ésta.

Desde luego no se trata de una simple crítica: «No estamos denunciando aquí una incoherencia de lenguaje o una contradicción de sistema. Nos preguntamos acerca del sentido de una necesidad: la de instalarse en una conceptualidad tradicional para destruirla. ¿Por qué se le ha impuesto finalmente a Levinas esta necesidad? ¿Es extrínseca? ¿Afecta sólo a un instrumento, a una "expresión" que podría ponerse entre comillas? ¿O bien oculta, esa necesidad, algún recurso indestructible e imprevisible del logos griego? ¿Una especie de potencia ilimitada de envolvimiento en la que quien quisiera rechazarlo quedaría siempre ya sorprendido?n, 16

La resistencia de la ontología greco-europea a su traducción o trasposición en una metafísica de la alteridad de inspiración judía (pero también la dificultad de traducir el pensamiento heterológico al lenguaje ontológico) coincide con la necesidad de una violencia irreductible en la historia de la cxperiencia y en el ser. Violencia pre-ética pero que la ética no podría ignorar, violencia originaria. Derrida hace ver la virulencia de ésta en tres instancias: la "polémica originaria" como ley de la experiencia de la consciencia según la dialéctica hegeliana, la eviolencia trascendental» que subyace a la intersubjetividad pensada por Husserl, y la "violencia ontológica» que deja ver el pensamiento del ser en Heidegger. En suma, puede decirse que lo que hace Derrida es someter a cuestión las críticas de Levinas a Hegel, Husserl y Heidegger, mostrando que tales críticas no hacen justicia a los recursos con que cuenta en cada uno de ellos el lenguaje filosófico, y concretamente sus recursos frente a la inspiración heterológica judía.

La polémica de Levinas con Hegel, o con la idea hegeliana de una polémica originaria, se resume en el rechazo de la negatividad. Es que el trabajo de la negatividad sería una apropiación violenta de lo Otro por lo 
Mismo que impediría la trascendencia y la relación heterológica por excelencia, el deseo de lo infinito. Ahora bien, esa crítica de la negatividad hegeliana como violencia apenas puede sostenerse en cuanto se toma consciencia de las condiciones del lenguaje, y ante todo de las condiciones del propio lenguaje. En efecto, y por vía de un ejemplo muy significativo, el análisis que Derrida hace del recurso levinasiano al término "exterioridad» para designar la alteridad del rostro como infinito positivo hace ver tanto la irreductibilidad de la metáfora en el lenguaje como la pertenencia de éste a una praxis espacial finita. El sentido filosófico --aquí la «exterioridad" como infinito positivo puro, sin mezcla de negatividad dialécticaestá finalmente cogido en su necesaria deportación metafórica a la estructura espacial finita del "dentro-fuera», y sometido a la naturalidad espacial de nuevo finita del lenguaje cotidiano. Si esto es así - y nadie como Hegel habría sido tan consciente de la implicación dialéctica entre las lenguas «naturales» o históricas y la lengua especulativa-, se hace dudosa la posibilidad de lo que intenta Levinas: exponer filosóficamente la alteridad infinita del otro previa reducción de la negatividad. La metaforicidad y la espacialidad, en suma la finitud del lenguaje impedirian la tesis, la posición del otro infinitamente otro o infinitud positiva: $\propto$ Así, pues, si no puedo designar la alteridad irreductible (infinita) del otro más que a través de la negación de la exterioridad espacial (finita), es quizás que su sentido es finito, no es positivamente infinito. Lo infinitamente otro, la infinitud de lo Otro no es lo Otro como infinitud positiva, Dios o semejanza con Dios. Lo infinitamente otro no sería lo que es, otro, si fuera infinitud positiva y si no guardase en él la negatividad de lo indefinido, del apeiron.${ }^{17}$ Un pensamiento de lo infinito tendría entonces que romper con el lenguajc y recaer en alguna especie de teología negativa. Ahora bien ese recurso se lo impide a sí mismo Levinas, quien a lo largo de Totalidad et Infinito insiste en que el rostro del otro es cuerpo y palabra.

Sobre todo, la negatividad dialéctica reclama sus derechos o la necesidad de su pertinencia en cl pensamiento de lo infinito que pretende excluirlo, en la medida en que hace ver la complicidad de violencia y paz en la experiencia histórica. Como vimos, Levinas eleva su discurso ético en el horizonte escatológico de una paz perfecta. Pero si el pensamiento de lo infinito está sometido a las condiciones espaciales y finitas del lenguaje, si éste es, así, originalmente violento, la diferencia entre paz y guerra no puede ya ser absoluta. La polémica es originaria e irreductible. No ya sólo el Rostro estaría implicado en la violencia, o en una relación con la violencia, en la medida en que ingresa en el lenguaje y en la historia: el mismo Dios, el nombre propio de lo infinito estaría mezclado en la guerra. ${ }^{18}$

El segundo paso en que Derrida pone en evidencia el conflicto entre el pensamiento heterológico y el lenguaje filosófico consiste en mostrar la dependencia de Levinas respecto a Husserl. Esto equivale a afirmar una 
violencia trascendental previa a la paz ética. Aquella dependencia fenomenológica resulta innegable - a pesar de las críticas de Levinas al idealismo y al teoreticismo de Husserl- en la medida en que el pensamiento de lo otro infinito mantiene la herencia de la teoría o de la luz al aceptar el principio metódico de la descripción intencional como respeto al objeto. Por otro lado, la intencionalidad tal como la propone Levinas, esto es, como estructura de la relación trascendente, y así, como relación esencialmente inadecuada de lo Mismo y lo Otro, era ya un tema literal husserliano. Ahora bien, la crítica principal de Levinas a Husserl concierne directamente a la interpretación de la intersubjetividad. El deseo del otro como relación asimétrica entre el ser separado y el Rostro no parece poder encajar en la relación trascendental del ego y el alter ego descrita en la célebre $5{ }^{\text {a }}$ de las Meditaciones cartesianas. En lo que Levinas insiste es en la asimetría de la relación, hasta el punto de que la misma expresión alter ego, la atribución al otro de una egoidad igual a la propia, sería en rigor inaceptable. La argumentación de Derrida aquí viene a ser una jerarquización, una distinción de niveles: si en el nivel ético cabe, o se requicre, la asimetría entre el yo y el otro, en el nivel de la intersubjetividad trascendental, que es previo, se impone una relación simétrica: «la simetría trascendental de dos asimetrías empíricas».19

Paralelamente a la originariedad irreductible de la guerra en el campo de la experiencia histórica, la anterioridad de la intersubjetividad como tal a la relación ética significa la necesidad de una violencia trascendental pre-ética. Esa necesidad arruina el pacifismo absoluto de la ética metafísica levinasiana, o más exactamente, amuina su pretensión de exponerse en el lenguaje ontológico y trascendental de la filosofía. Aquí se hace patente la hipótesis señalada más arriba, según la cual ninguna novedad podría "sorprender" totalmente a la indestructible reserva griega de la filosofía. La dialéctica de lo mismo y lo otro tal como se desarrolla, por ejemplo, en El Sofista de Platón, podría fundar, en cuanto onto-logía que hace ser a lo otro lo mismo (que sí) y a lo mismo lo otro (que lo otro), la ética heterológica. Ésta, contra la pretensión de Levinas, sería entonces derivada o secundaria. En esa misma motivación, en coherencia con la hipótesis de una repetición del origen griego, se inscribiria lo que el propio Derrida llama su "sordera» ante la declaración levinasiana de una escisión originaria del ser en lo Mismo y lo Otro. ${ }^{20}$

En tercer lugar Derrida considera, bajo el título de la «violencia ontológicas, la crítica de Levinas a Heidegger. Crítica, o más bien rechazo alérgico de Levinas a un pensamiento al que sin embargo y según reconoce él mismo ${ }^{21}$ le debe mucho. Ese rechazo se precisaría en una interpretación abiertamente ético-política del tema heideggeriano de la diferencia ónticoontologica: la diferencia entre el ente y el ser, y el primado de la comprensión del ser sobre el conocimiento del ente significarían, según Levinas, 
una prioridad del ser anónimo y neutro sobre el ente individual y personal, esto es, una violenta secundarización de la relación ética. La estrategia de la respuesta de Derrida a esa a su vez "violenta" toma de posición de Levinas, y en paralelo a los dos pasos anteriores, es doble. Por un lado es necesario defender el pensamiento del ser de esa interpretación unilateral y reductiva, haciendo ver que no cabe hacer de él una lectura inmediatamente ética. Pensar la diferencia del ente y el ser, y la originalidad no categorial de la comprensión del ser no significa en ningún caso afirmar algo así como una prioridad, ni óntica ni ética, del ser sobre el ente. Puesto que el ser precisamente no es un ente, entre el uno y el otro no caben relaciones de jerarquía, dominación o violencia. ${ }^{22}$ Por otro lado, la metafísica del rostro y la ética de lo infinito suponen el pensamiento del ser. No se trata de un dato en la biografia intelectual de Levinas, sino de una necesidad esencial de la cosa. Al afirmar, por ejemplo, "la exterioridad como esencia del ser», Levinas de hecho pone en práctica en su discurso el pensamiento del ser que pretende recusar. Así, pues, Levinas oculta lo que supone: "La metafísica del rostro encierra, pues, el pensamiento del ser, presupone la diferencia entre el ser y el ente al mismo tiempo que la silenciam.23

Ahora bien, lo que excluye Derrida del pensamiento del ser es la violencia ética, no cualquier o toda violencia. Puesto que el ser no es un ente (primero o perfecto), puesto que se da, se desvela y se oculta, se determina o se delimita en el ente, en suma, puesto que el ser es desde el origen historia y mundo, el pensamiento del scr no puede ser extraño a la violencia. La violencia y la guerra no son accidentes que sobrevengan al ser desde el momento en que éste es pensado, fuera de la metafísica, como siendo de parte a parte historia y mundo. ${ }^{24}$ Como se ha sugerido ya, no se trata por parte de Derrida simplemente de una "aclaración" hermenéutica ante la interpretación parcial que da Levinas de Heidegger. Se trata también y sobre todo de apuntar a una incoherencia en el discurso filosófico de Levinas. La clave de la diferencia de éste respecto al de Heidegger residiría en su aparentemente radical tesis de una a-historicidad del sentido. Decimos «aparentemente" porque no es seguro que esa ahistoricidad sea compatible con la idea de una originalidad irreductible de la palabra. Si hay lenguaje, el paso a la frase, a la determinación predicativa y conceptual, y así, a la violencia, es inevitable. Levinas sólo podría eludir la violencia conceptual del lenguaje histórico arriesgando la peor violencia, la del silencio.

\section{De la ontología a los tropos del lenguaje ético}

La critica de Derrida al Levinas de Totalidad e Infinito se resume en una cuestión de lenguaje: en la evidenciación de una incoherencia entre su intención heterológica y su discurso filosófico. Incoherencia puesto que, 
como se ha visto a propósito de Hegel, de Husserl y de Heidegger, el discurso filosófico como tal mantiene el fondo griego de un pensamiento de lo mismo ( $\mathrm{y}$ así, de la violencia originaria). En el texto de Levinas esa incoherencia toma el nombre de empirismo, la decisión filosófica de renunciar al concepto o a la filosofía. A lo que Derrida califica de «sueñon: el sueño de un pensamiento heterológico puro. ${ }^{25}$ Sueño porque no resiste la luz del día, ni la del lenguaje. Cierto, esta crítica es inseparable de una lectura que es al mismo tiempo el reconocimiento en el "empirismo" de Levinas de una audacia y una profundidad especulativas inéditas. Pero Totalidad e Infinito deja impensado el problema de la relación, en la concreta articulación y economía de su texto, entre lo filosófico y lo heteroló gico, entre la lógica griega y el profetismo escatológico. Ese problema adquiere en cambio una relevancia tal en De otro modo que ser o más allá de la esencia que en rigor dicha cuestión aparece ahí indesligable de las atesis» fundamentales de esa obra.

Sin duda el desplazamiento teórico principal en el paso de Totalidad e Infinito a De otro modo que ser... reside en el abandono del lenguaje ontológico. La segunda versión de la "Signature» que cierra Difficile Liberté ( $2{ }^{a}$ ed., 1976) nombra directamente este motivo como determinante de la diferencia entre el libro de 1961 y los textos posteriores: tanto el propio $D e$ otro modo que ser... como los ensayos que preparan y prolongan esa obra ( La huella del otro" y "Lenguaje y proximidad", incluidos en la $2 .^{\text {" }}$ edición de Descubriendo la existencia con Husserl y Heidegger, 1967; Humanismo del otro hombre, 1972; y "Dios y la filosofía", 1975, incluido en De Dios que viene a la idea). Dice, pues, Levinas, en la comprometida rúbrica de su autobiografia: «El lenguaje ontológico del que se sirve todavía Totalidad e Infinito para excluir la significación puramente psicológica de los análisis propuestos es evitado en adelante $»{ }^{26} \mathrm{~A}$ decir verdad los términos de esa fórmula sugieren en principio que el desplazamiento concierne menos al "contenido" de unas tesis que a la estrategia de su presentación. De hecho, en ese lenguaje ontológico se había expuesto incluso la tesis del primado de la metafísica sobre la ontología. Pero esa minimización del alcance del cambio efectuado entre las dos obras principales de Levinas no da cuenta de sus diferencias: de lenguaje, de método, y de orientación. ${ }^{27}$

No podemos abordar aquí ni siquiera el esquema de una lectura sistemática de De otro modo que ser... -que tendría que tener en cuenta su resistencia articulada al sistema y al tema o a la tematización, a lo Dicho o al logos-. Nos limitamos a situar aquí más precisamente en esa obra la cuestión cuyo hilo hemos seguido a propósito de Totalidad e Infinito: la de la diferencia greco-judía en el discurso filosófico de la ética metafísica del rostro. De nuevo, pues, una cuestión de lenguaje.

El "germen" de De otro modo que ser..., en un sentido no meramente cronológico, es su capítulo IV: "La sustitución». ${ }^{28}$ Levinas vuelve a pensar 
ahí, con una concentración expresiva y un aliento teórico inéditos, el «viejon tcma de la subjetividad. Ésta no es aquí, como era en Totalidad e Infinito, el ser separado o "ateo" y apclado a una responsabilidad moral por el rostro del otro, sino, previamente y ante todo, antes de todo principio o anárquicamente, la contracción dramática de una responsabilidad por el otro contraída antes de poder haber sido asumida. Esa subjetividad es, entonces, en su núcleo precisarnente vulnerable, ser-para-el-otro, pérdida de la propia identidad, psiquismo como psicosis o locura, en fin, ser-en-ellugar-del-otro o sustitución. Que esa sustitución no responda al esquema de lo que el pensamiento contemporáneo ha criticado como alienación es una de las preocupaciones constantes de la descripción de Levinas. Pero, y éste es nuestro problema, ¿qué lenguaje puede hacer justicia a esa subjetividad que en su núcleo, por eso mismo fisurado, sería sustitución del sí mismo por el otro, pérdida de la identidad? El lenguaje ontológico está de entrada excluido, como que esa subjetividad se muestra justamente como una excepción a las leyes de la esencia, del ente, y de la diferencia del ser y. el ente. Ahora bien, al mismo tiempo este discurso no ontológico se presenta como filosófico en su fidelidad intelectualista a una descripción heterogénea a la palabra profética.

De otro modo que ser... afronta abiertamente el problema planteado en dos contextos que con cierta artificiosidad aislamos de la trama de la obra. El primero de ellos es el de la trasposición del lenguaje ontológico a los tropos del lenguaje ético. El segundo, en última instancia indisociable del primero, es el tema del límite esencial de la tematización, la inadecuación entre el Decir y lo Dicho. Levinas apela concretamente - y con una insistencia característica a lo largo del citado capítulo IV- a un recurso trópico o tropológico, más que metafórico, al explicar el sí mismo de la subjetividad en su recurrencia o su repliegue prerreflexivo. Como sí mismo, la subjetividad escapa a la categoría como tal, esto es, a la significación lógica que se acusa en o que informa una materia preexistente. Es que el sujeto, como el uno en la primera hipótesis del Parménides, no puede recurrir al ser, o está expulsado del ser, está fuera del ser, sin fundamento o sin suelo. De ahí la modalidad del sujeto: «En su piel; de ningún modo en reposo bajo una forma, sino a disgusto en su piel, obstruido y como tapado por sí, sofocado bajo sí mismo, insuficientemente abierto, forzado a desprenderse de sí, a respirar más profundamente hasta el final, a desposeerse hasta perderse» ( $A E$, pp. 140-141; trad. modif. p. 178). Ahora bien, esos términos —el estrechamiento, el sofoco, la obstrucción del sî mismo que obliga a éste a salir de sí- no serían, como cabría pensar, "metáforas": más bien "siguen el tropo exacto de una alteración de la esencia que se invierte -o se da la vuelta- en una recurrencia donde la expulsión de sí fuera del sí es sustitución del otro, lo cual significaría propiamente el Sí mismo vaciándose de sí mismo» (ibid., trad. modif.; he subrayado "tropo 
exacto»). El tropo de la sustitución no es una «figura» que expone literariamente $\mathrm{u}$ ornamentalmente y como sobreañadido un sentido literal previo. Aquí es precisamente un tropo exacto. ${ }^{29} \mathrm{La}$ descripción y la exposición de éste permiten avanzar (o retroceder) hasta la raíz pre-ética de la responsabilidad moral que sería esa sustitución del uno-para-el-otro en el sí mismo. El núcleo precisamente por eso no atómico de la subjetividad sólo es pensable entonces al margen de las categorías ontológicas de la esencia, la identidad y la sustancialidad: «El sí mismo debe pensarse al margen de toda coincidencia sustancial de sí consigo, y sin que la coincidencia sea, como pretende el pensamiento occidental que une subjetividad y sustancialidad, la norma que rige ya toda no-coincidencia, rigiéndola bajo las especies de la investigación que suscita. Desde ese momento, la recurrencia a sí puede no detenerse en sí, sino ir más acá de sí, en la recurrencia a sí ir más acá de sí. A no se reduce a $A$, como en la identidad, sino que retrocede más acá de su punto de partida. ¿No se dice la significación de la responsabilidad para otro - no asumible por una libertad cualquicrasegún ese tropo?» (AE, p. 145; trad. modif. p. 182).

Así, pues, sería una grosera simplificación hermenéutica entender que Levinas pasa en De otro modo que ser... del lenguaje ontológico al lenguaje ético. Paso que sería difícil separar del recurso acrítico y prefilosófico al discurso edificante o moralista. Para dar cuenta del fenómeno común y extraordinario de la responsabilidad moral por el otro más allá del cálculo razonable se requiere descripción, fenomenología, filosofía. En esa línea: «El lenguaje ético al que hemos recurrido no procede de una experiencia moral especial, independiente de la descripción desarrollada hasta ahora. La situación ética de la responsabilidad no se comprende a partir de la éticas ( $A E$, p. 154; trad. p. 191; subrayado mío). La responsabilidad radical es previa a la obligación que se le impone a una voluntad a través de su asociación con otras voluntades que conforman así una comunidad ética. La responsabilidad está ya en el sí mismo previo a la formación de la voluntad en el ego racional. En este sentido, la descripción de la subjetividad como sustitución y ser-para-el-otro es anterior filosóficamente a la moral. De nuevo, es una trópica por así decirlo interna al lenguaje ético lo que orienta esta salida de la ontología - que no quierc sin embargo recaer en el discurso piadoso o cdificante, ni en la teología-: «Los tropos del lenguaje ético se encuentran adecuados a ciertas estructuras de la descripción: en el sentido del acercamiento que contrasta con (tranchant sur) el saber; del rostro que contrasta con el fenómenon ( $A E$, p. 155; trad. modif. p. 192).

La descripción no-ontológica de la subjetividad y la serie de conceptos o de tropos que aquella requiere - sustitución, persecución, obsesión, pasividad, vulnerabilidad, sensibilidad, recurrencia, proximidad, inspiración o profetismo- contrastan ciertamente con las formas dominantes de la tra- 
dición filosófica occidental en tanto ésta se mantiene unívocamente fiel a su ancestro griego. (Ese "contraste» puede llegar al límite de una irrecibibilidad del discurso levinasiano en una parte significativa de la comunidad filosófica, incluso o sobre todo por parte de la que se llama a sî misma ética del discurso y de la comunidad de comunicación). Ya sabemos que para Levinas, sin embargo, no se trata de oponer simplemente al helenismo dominante de la filosofía un pensamiento judio inspirado en la Biblia y el Talmud, sino más bien de articular aquella diferencia en una traducción de lo no-helénico de la Biblia en los términos universales legados por Grecia ${ }^{30}$ Esa traducción - ejercida más bien que pensada ya en Totalidad e Infinito- es tema de una reflexión continua por no decir obsesiva en las páginas de De otro modo que ser... El "programa» de este libro suscita de entrada el problema metodológico mayor de una (aparentemente inevitable) incoherencia sistemática entre su rechazo de la ontología en la "paciencia del rechazo del concepton ( $A E$, p. 162; trad. p. 199) y el recurso implícito a la ontología de un discurso predicativo que dice en cada frase «es». De ahí que Levinas plantee este problema en el texto por así decirlo performativamente, como pregunta por la posibilidad de un discurso que «en este momento, en la presente obra" parece incumplir lo que propone, esto es, la delimitación y la reducción si no el abandono simple de la ontología. ${ }^{31}$ De ahí también que Levinas plantee este problema como el problema del límite de la tematización, límite que se hace visible en la inadecuación del Decir y lo Dicho: el Decir, la apertura de una pasividad anterior a toda identidad, y así, pre-original o an-árquica, queda traicionada al traducirse al lenguaje apofántico que, en su forma, expone lo que es. Se advierte la envergadura de la cuestión ya desde el principio, en la exposición primera de su «argumento»: «Aquí se plantea un problema metodológico. Tal problema consiste en preguntarse si lo pre-original del Decir (si la anarquía, lo no-original como lo designamos) puede ser conducido a traicionarse al mostrarse en un tema (si una an-arqueología es posible) y si tal traición puede redimirse; es decir, si se puede al mismo tiempo saber y liberar lo sabido de las señales que la tematización le imprime al subordinarlo a la ontología. Una traición al precio de la cual todo se muestra, incluso lo indecible, y gracias a la cual es posible la indiscreción respecto a lo indecible, lo cual probablemente constituye la tarea misma de la filosofía» (AE, p. 8; trad. p. 50).

Pero la verdadera envergadura de la cuestión aparece sobre todo en el capítulo final especialmente en los epígrafes 3 y 5 ("Del Decir a lo Dicho" y "Escepticismo y razón»). El Decir coincide con la subjetividad: no es, por tanto, a pesar de su apariencia, actividad sino pasividad, responsabilidad anárquica o preoriginal, significación o tropo de lo-uno-por-lo-otro antes de toda ontología. Lo Dicho es el logos apofántico que, idealmente al menos, enuncia sistemáticamente el reino de la esencia y el fenómeno. Ahora 
bien, el discurso mismo que expone la diferencia entre el Decir y lo Dicho entra en el terreno de lo Dicho. La objeción de incoherencia surge entonces fácil. La respuesta de Levinas remite en primera instancia al tiempo, a la diacronía del discurso: contradicción habria sólo entre dos enunciados simultáneos, no en cambio entre el enunciado que dice o significa el más allá del ser y la reflexión sobre las condiciones apofánticas y así ontológicas del enunciado (cf. $A E$, pp. 198-199; trad. pp. 234-235). Pero sigue habiendo un problema en el hecho de que el Decir no pueda dejar de "cacr" en lo Dicho. Esa necesidad coincide con la necesidad de la ontología tal como la filosofía occidental la ha elaborado, esto es, como nivel primero o último de la significación. Así, el discurso del más allá del ser tiene que habérselas con el problema del lugar de la ontología que es también el problema del nacimiento del saber y de la filosofía: "Pero es ya hora de mostrar el lugar que esta síntesis apofántica, fuente de la sustracción (stubreption) que confiere a la ontología el lugar del último cuestionamiento, esta síntesis más formal que lo formal, ocupa en el pensamiento que piensa más allá del ser. No es por azar, por tontería o por usurpación por lo que el orden de la verdad y de la esencia -en el que la misma exposición presente intenta mantenerse- ocupa el primer rango en la filosofía occidental. ¿Por qué la proximidad, pura significación del Decir, el-uno-parael-otro an-árquico de más allá del ser, retomaría al ser o caería en ser, en conjunción de entes, en esencia que se muestra en lo Dicho? ¿Por qué hemos ido a buscar la esencia en su Empíreo? ¿Por qué saber? ¿Por qué problema? ¿Por qué filosofía?» (AE, p. 199; trad. modif. p. 235).

La clave de la respuesta al problema del origen del problema es la aparición del tercero. Un motivo que había sido ya muy eficaz en un contexto paralelo de Totalidad e Infinito, a propósito de lo que cabe llamar el "racionalismon de la ética del rostro. La relación del sí mismo y el otro como responsabilidad y sustitución es asimétrica. Pero si el otro es otro entre otros, tiene que entrar en juego la justicia, la comparación, la objetividad. De la significación en sentido o dirección única o responsabilidad por el otro o Decir, se pasa al sentido como inteligibilidad común o universalizable, a la comparación, la contemporaneidad, la conjunción, la tematización, en fin, al orden de lo Dicho (cf. $A E$, p. 202; trad. p. 237).

Así, si primero el Decir parece contradictorio con su conversión en lo Dicho, ahora aparece más bien que aquél requiere la tematización en el logos. La objetividad y la justicia no son originales, pero sí se derivan de la significación pre-originaria o de la responsabilidad descrita a través de los tropos del lenguaje ético. ¿Esa descripción es ella misma filosofía? Desde luego su heterogeneidad respecto a la forma dominante de la filosofía occidental no podría minimizarse. Este cuestionamiento abierto de la ontología en el discurso filosófico es una ruptura -que puede escandalizar como un «irracionalismon, desmentido sin embargo a cada paso por Levinas- 
con el cuadro categorial que ha dado a la filosofía algo más que su léxico y su sintaxis, también su axiomática. Pero este texto de Levinas es también, o todavía, filosofía. Entiende y practica ésta como la difícil negociación de un traductor entre dos lenguas y aunque la analogía tiene el límite esencial y obvio de que el Decir y lo Dicho no se pueden confrontar entre sí como dos lenguas, Levinas emplea en este contexto el término, de filiación fenomenológica, "reducción». La filosofía sería la reducción de una inevitable traición producida en la traducción de la responsabilidad preoriginal al logos dicho. ${ }^{32}$ La legitimidad de la filosofía es indisociable de la ambivalencia de un discurso que sincroniza o tematiza pero que se mantiene como "servante du Dire» ( $A E$, p. 206; trad. p. 242), como ancilla del lenguaje ético-trópico. Ambivalencia, o más bien desgarramiento como el que divide al «hipócrita» entre la búsqueda filosófica de la verdad y la exigencia profética del bien. ${ }^{33}$

Ambivalencia y desgarramiento caracterizan abiertamente, en cualquier caso, lo que cabe llamar el «tono" de las últimas páginas de De otro modo que ser..., las que describen la alternancia del Decir y lo Dicho como alternancia del escepticismo y la razón. A la refutación clásica -lógica y trivial- del escepticismo como autocontradictorio, éste puede responder a partir de la diacronía del lenguaje que pone un intervalo entre el Decir y lo Dicho. El escepticismo es refutable pero vuelve siempre recordándole a la razón su mortalidad, y su violencia. El racionalismo ingenuo no podrá ya tener la inocencia de la lógica. Los desgarrones del texto o el tejido lógico no puede volverlos a coser la lógica simplemente o la razón tout court. A la filosofia, a la que le corresponde la tarea de reconstruir permanentemente una razón en constante peligro, no puede escaparle el supuesto estatal, político o médico, de la razón: «En la asociación de la filosofía y el Estado, de la filosolía y de la medicina, es donde se supera la ruptura del discurso. El interlocutor que no se somete a la lógica es amenazado de prisión y de asilo o sufre el prestigio del maestro y la medicación del médico; la violencia, la razón de estado o el acercamiento aseguran al racionalismo de la lógica una universalidad y a la ley su materia sumisa. Por tanto, el discurso recupera su sentido mediante la represión o la medicación, mediante las justas violencias en el límite de la injusticia posible, en el que se mantiene la justicia represiva. La razón y el saber son fuerza y eficacia mediante el Estado" ( $A E$, p. 216; trad. p. 251).

En lo anterior no debería verse desde luego un rechazo simple del Estado, la política y el derecho (y la medicina y la escuela). Lo cicrto es que el "segundo" Levinas es más "negociador" que cl de Totalidad e Infinito con la política: ésta no es ahora, como fue en el pacifismo absoluto y escatológico del primer libro, la guerra llevada por otros medios. De otro modo que ser... sitúa la necesidad y la legitimidad de la razón y el cálculo, y así, también, del Derecho y el Estado. Análogamente: el racionalismo 
griego sigue siendo la condición de posibilidad histórica de la filosofía al darle a ésta su lengua fundamental, el logos apofántico de la esencia. Pero por otro lado esta obra explora con una nueva profundidad el profetismo, y como algo más o algo diferente de lo que Totalidad e Infinito llamó el extraordinario fenómeno de la escatología mesiánica que aparece "históricamente» en la existencia de un pueblo. El profetismo se describe en De otro modo que ser... como una estructura del psiquismo en tanto sustitu-

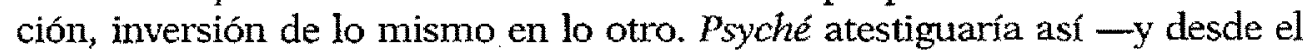
ritmo biológico de la respiración-, la gloria de lo infinito o de la eleidad. Pero la pertinencia por así decirlo estructural del profetismo al psiquismo no le da a aquél la seguridad o la certeza de una necesidad eidética, ni tampoco el carácter de "remedio sustitutivo de una revelación manca" (AE, p. 194; trad. p. 230). Por el contrario, es esencial al profetismo su enigmática ambivalencia, "posibilidad a la vez de ideología y de delirio sagrado». Y si la ciencia - la filología, la psicología, la sociología- deben eludir o purificar la ideología y la retórica, el intelectualismo levinasiano sigue asignándole a la filosofía, entre otras cosas, la tarea de reducir el delirio sagrado y su tendencia a la participación mágica en la trascendencia.

Así, el paso de Totalidad e Infinito a De otro modo que ser... no habrá sido un desplazamiento desde la filosofia como ontología de la razón griega a la filosofía como interpretación de la palabra profética judía. Habrá sido más bien una profundización, otra vuelta de tuerca, en la explicación interna de la diferencia greco-judía, una nueva dramatización de ese desgarramiento o de esa hipocresía.

\section{NOTAS}

1. Totalité et Infini, La Haya, M. Nijoff, 1961, p. XVI; trad. esp. de Daniel Guillot, Salamanca, 1977, p. 54. Citaremos esta obra en adelante en el mismo texto por las siglas $T I$. Sobre Maimónides, como una acima en el judaísmo" y como otra cosa que una contingencia en la historia sagrada, cf. $A$ theure des nations, Paris, 1988, pp. 197 y ss. Un paso de Totalidad $e$ Infinito (p. 43) recuerda la idea platónica de idea de Hermann Cohen, evocado también en "Entre deux mondes» (Difficile Liberté, 2." ed., París, 1976) como maestro en los estudios judios de Franz Rosenzweig. A Buber se refiere también Totalidad e infinito (pp. 40 y ss.) en el contexto de una necesaria diferenciación de posiciones. El diálogo entre la filosofia buberiana del yo-tú y la ética metafísica levinasiana se prolonga en "Dialogue avec Martin Buber", en Noms propres, París, 1976, pp. 51 y ss. En fin, a Franz Rosenzweig le ha dedicado Levinas dos estudios importantes: el mencionado "Entre deux mondes" (1959) y "La filosofía de F.R." (prefacio a Système et révelation de S. Mosès, de 1982; también en À liheture des nations, op. cit.).

2. El tema del fracaso moral histórico del racionalismo europeo es un motivo recurrente en los ensayos de Difficile Liberté, y también un "supuesto" contextual de muchos movimientos de Totalidad e infinito, por ejemplo de sus primeras páginas sobre la guerra y la paz. En algun momento Levinas llega a decir o a decirse que "Auschwitz ha sido cometido por la civilización del idealismo trascendental», cf. F.Poirié, Emmanuel Levinas, París, 1987, p. 84. 
3. Cf. el importante estudio de Catherine Chalier, "Singularité juive et philosophie», en Les cahters de la nuit surveille. Enmanuel Levinas, Paris, 1984, pp. 78-99; cf. tambiên, en el nismo volumen, David Banon, "Une herméneutique de la sollicitation. Levinas lecteur du Talmudx.

4. Cf. Difficile Libenté, op. cit., sobre todo los ensayos agrupados bajo los epígrafes aMás allá de lo patético» y «Polémicas». Por otra parte, cabe notar cambios importantes en la cvolución de Levinas a propósito de la relación judaismo-cristianismo. Así, por ejemplo, en A theure des nations, op. cit., pp. 189 y ss.

5. Difficile Liberte, op. cit., "Textes messianiques", pp. 89-143.

6. Cf. F. Poirie, Emmanuel Levinas, op. cit, pp. 125 y ss.

7. Decimos esto, claro está, de la religión en el sentido corriente, si así puede decirse. En ocasiones Levinas recurre a ese término como elemento o vicisitud de su pensamiento filosófi$\mathrm{ca}$, pero precisamente entonces se confima que no estamos ante una filosofia condicionada o determinada por una o la religion. Así, al proponer "llamar religión al lazo que se establece entre lo Mismo y lo Otro sin constituir una totalidad" (Totalite et Infini, op. cit, p. 10).

8. Sobre los diferentes conceptos de infinito, en Descartes, Kant y Hegel, cf. ibid. pp. 169 y ss.

9. Sí lo hace en «La philosophie et l'idée de l'infini», que se presenta como una anticipación del libro. Cf. En découvrant lexistence avec Husserl et Heidegger, 2." ed., París, 1967. pp. 165 y ss.

10. Ha insistido en este tema P.A. Rovatti en Cono la luz tentse. Metufora y saber, Barcelona, 1990.

11. Una amplia y concreta confirmación de la fidelidad lcvinasiana al intelectualismo puede encontrarse en lo que cabe llamar el racionalismo de su filosofía del rostro. La fenomenología ética del rostro repite la fundamentación de la racionalidad y del lenguaje objetivo, de acuerdo con algunos de los análisis centrales de Levinas. $C f$. esp. $T I$, pp. 62-74 y pp. 176-186.

12. Importante al respecto es el ensayo "Réflexions sur la "technique" phénoménologique» (1959), en En découmant lexistence..., op. cit., pp. 111 y ss. La fidelidad intelectual al método fenomenológico, a pesar de todas las variaciones a que lo somete, es una constante de la obra de Levinas, tanto en Totalidad e Infinito, como en los escritos principales posteriores. Se refiere a ello en la entrevista con Ph. Nemo, Ethique et Infini, París, 1982, pp. 24 y ss.

13. J. Demida, La escritura y la diferencia, Barcelona, 1989, pp. 107-211.

14. En este sentido se manifiesta Ulpiano Vázquez Moro en El discurso sobre Dios en la obra de Levinas, Madrid, 1982, pp. 61 y ss. Al respecto pueden consultarse también los estudios de E. Feron, "Êthique, langage, ontologie chez Levinas", Revue de Métaphysique et Morale, 82 (1977), 64-87; de J. de Greef, "Empirisme et Éthique chez Levinas", Archives de Philosophie, 33 (1970), pp. 223-241 y de R. Bemasconi, "Deconstruction and the Possibility of Ethies», en J. Sallis (ed.), Deconstruction and Philosophy, Chicago, 1985. Se consultará también S. Petrosino y J. Rolland, La vérité nomade, Paris, 1984. Una perspectiva aguda sobre la critica de Derrida a Levinas, en M. Ferraris, "L'esclusione della filosofia. Ebraismo e pragmaussno", Aut-Aut, 213 (1986), ahora en Postille a Derrida, Torino, 1990.

15. J. Derrida, La escritura y la diferencia, op. cit., p. 111.

16. Ibid, p. 150.

17. Ibid, p. 153 .

18. Ibid. p. 144. Sobre el tema y el nombre de Dios, el último Levinas ha vuelto posteriormente. Destaquemos "Le Nom de Dieu d'après quelques textes talmudiques", in Latt-delà du verset, Paris, 1982, y sobre todo aDieu et la philosophie" in De Dieu qui vient à lidéé, París, 1982.

19. J. Derrida, La escritura y la diferencia, op. cit., p. 169.

20. Cf. ibid., p. 170.

21. Cf. por ejemplo, entre otros muchos lugares, Ethique et Infini, op. cit., pp 31 y ss.

22. J. Derrida, La escritura y la diferencia, op. cit., pp. 183-185.

23. lbid, p. 195. 
24. Tbid., pp. 195-196 y 200-201.

25. Bbid., p. 206. Me permito remitir aquí a Patricio Peñalver Gómez, Desconstnacción, escritura y filosofia, Barcelona, Montesinos, 1990, pp. 34-44.

26. Difficile Liberté, op. cit., p. 411.

27. Otro contexto en que Levinas considera el paso de Tatalidad e Infinito a De otro modo que ser... es el de las "Questions et réponses" incluidas en De Dieu qui vient à lidée, op. cit., espec. pp. 138-143.

28. Autrement qu'être ou au delà de lessence, La Haya, 1974, p. 124; trad. esp. de Antonio Pintor-Ramos, Salamanca, 1987, p. 163. En adelante citaremos esta obra en el mismo texto mediante las siglas AE. Para un estudio del paso de Totalidad e Infinito a De otro modo que ser, cf. S. Petrosino, "D'un livre à lautre. Totalité et Infint-Autrentent quêttren en Les cohtiers de la nuit suneitlee. Emmantul Levinas (ed. J. Rolland), París, 1984, pp. 194-211. Guy Petitdemange ha propuesto una penetrante aproximación a la "conclusion tourbillonante et difficile du livre majeur de Levinas" en "Emmanuel Levinas: au-dehors, sans retour», en Répondre d'autrui. Emmanuel Levinas (ed. J.Ch. Aeschlimann), Neuchatel, 1989, pp. 71-94.

29. Levinas se refiere al problema de la metáfora como tal, y en una perspectiva por cierto muy poco convencional, en Humanisme de lautre homme, Paris, 1972, pp. 17-23.

30. Cf. De Dieu qui vient à lidé, op. cit., p. 137.

31. Derrida interroga esos pasajes en los que el propio discurso de Levinas se refiere a sí mismo - no sin un matiz autoirónico que remeda el lenguaje universitario cuando éste se pliega en la autorreferencia mediante los een este trabajo, en esta obram- a lo largo de un largo y complejo ensayo de "negociacion» con la propuesta ético-profética de De otro modo que ser...: “En este momento en este trabajo heme aquí», trad. esp. en Suplementos Anthropos (Barcelona), 13 (1989).

32. Sobre el concepto de reducción, cf. $A E$, pp. 56-58 y 94-96.

33. En el contexto de un comentario a Blanchot, Levinas dice de sla palabra coherenten, la que "guarda las llaves de las puertas destruidas»: "i Maravillosa hipócrita! Pues ama la locura que vigilaw, Sur Maurice Blanchot, Paris, 1975, p. 41. 